\title{
A chapter called controversy: breaking down the Delhi high court appellate bench verdict in F Hoffmann-La Roche v Cipla Ltd
}

\author{
Eashan Ghosh \\ Intellectual Property Advocate, New Delhi and Seminar Faculty, National Law University, Delhi
}

On 27 November 2015, an appellate bench of the Delhi High Court in F Hoffmann-La Roche v Cipla Ltd issued a 184-paragraph opinion, overturning in part a 2012 single judge decision and holding that Cipla had infringed Roche's Indian patent over erlotinib hydrochloride. However, it turned out that large swathes of the appellate decision had been lifted verbatim from an article I co-authored for this journal in 2013. Alerted to the lapse, the bench issued a corrected order on 8 December 2015 and, in an unprecedented move, opted to expunge the plagiarized portions and issued an apology for the oversight. As a result, the rebooted ruling dives straight into the legal issues involved and, as this article posits, is no less explosive for its findings on merits than it was for the curious episode that created a buzz around it for all the wrong reasons. In doing so, the decision deviates from Indian precedent in a manner that could, in equal parts, be construed as path-breaking, unsettling and, above all, fiercely controversial.

Keywords: India, patents, Section 3(d), non-obviousness, patent infringement, polymorphs, $x$-ray diffraction, Roche v Cipla, plagiarism

\section{INTRODUCTION}

Roche's Indian patent (IN '774) over the anti-cancer erlotinib hydrochloride (EH) molecule ran out in March 2016. The patent, fortified by which Roche launched its version of the EH drug (Tarceva), led a tumultuous existence to say the least, having attracted non-stop litigation ever since its grant in February 2007. Arguably the most prominent of these cases was against Indian pharmaceutical heavyweight Cipla, which launched its version of the EH drug (Erlocip) in early 2008.

Roche promptly filed suit for infringement of IN ' 774 but, through several goarounds before the Delhi High Court at the preliminary injunction stage, ${ }^{1}$ Cipla was never once stopped from selling its version of the EH drug. Therefore, even the mere finding by the appellate bench that Erlocip infringes IN ' 774 was sufficient to grab the attention of the Indian patent law community.

The 2013 article I co-wrote for this journal ${ }^{2}$ on the post-trial verdict by Justice Singh of the Delhi High Court, ${ }^{3}$ was, at best, a circumspect endorsement of Justice

1. F Hoffmann-La Roche v Cipla Ltd 2008 (37) PTC 71 (Del); F Hoffmann-La Roche v Cipla Ltd 2009 (40) PTC 125 (Del).

2. S Majumder and E Ghosh, 'Winds of Change: F Hoffmann-La Roche \& Anr v. Cipla Ltd (CS(OS) No. 89/2008, judgment dated 7.9.12)' (2013) 3(2) Queen Mary Journal of Intellectual Property $167-75$.

3. F Hoffmann-La Roche v Cipla Ltd 2012 (52) PTC 1 (Del). 
Singh's findings. As such, the reproduction of those now-recanted observations in the original version of the appellate bench's opinion, ${ }^{4}$ which disposed of Roche's appeal to Justice Singh's decision, was surprising to begin with. However, for all the initial publicity the copied parts garnered on the plagiarism issue, ${ }^{5}$ they did provide a tether to the appellate bench's verdict, the absence of which is apparent in the final version of the decision.

Justice Singh had held in favour of Cipla, ruling that Erlocip did not infringe IN '774. In doing so, he made three key observations, all of which were assailed by Roche in appeal - first, that Claim 1 of IN ' 774 did not disclose a product that was the same as, or could be purposively read to cover, Roche's product Tarceva; second, that Cipla had failed to lead sufficient evidence on whether IN ' 774 was merely a new form of an old substance and therefore disqualified from patentability under Section 3(d) of the Indian Patents Act, and finally, that the very factum of Roche filing an (ultimately rejected) improvement patent application for a Polymorph B-only version of EH in India (IN '507), in effect, knifed IN ' 774 to the extent that Roche could not use IN '774 to block other EH formulations that were avowedly Polymorph B alone (such as Erlocip).

Thirty-eight months later, the dust has finally settled on the substantial disagreements of the Appellate Court ('the Court' hereafter) with each of these conclusions, which are now taken up in turn.

\section{THE SECTION 3(D) QUESTION}

\subsection{Square pegs, round holes}

Section 3(d) of the Indian Patents Act provides a patentability check on new and derivative forms of known substances, which are not considered inventive unless they demonstrate superior efficacy. This is manifest not so much from the confusingly phrased statute but from a sizeable body of judicial work capped by the Indian Supreme Court, ${ }^{6}$ which this Court relies on extensively. ${ }^{7}$

4. F Hoffmann-La Roche v Cipla Ltd, judgment dated 27 November 2015 by the Delhi High Court (per Nandrajog and Gupta JJ) in RFA (OS) 92/2012 and 103/2012, at paragraphs 4-37 <http://lobis.nic.in/ddir/dhc/PNJ/judgment/27-11-2015/PNJ27112015RFAOS922012.pdf> accessed 22 December 2015.

5. A Garg, 'Law Intern Copies Tracts of Article into HC Ruling' <http://timesofindia.india times.com/india/Law-intern-copies-tracts-of-article-into-HC-ruling/articleshow/50100432.cms> accessed 22 December 2015; S Barooah, 'Copyright Issues in Roche v. Cipla?' <http://spicyip. com/2015/12/copyright-issues-in-roche-v-cipla.html> accessed 22 December 2015; A Anuja and AK Aditya, 'Delhi High Court Owns Up to Plagiarism Charges after Intern's Gaffe' $<$ http://barandbench.com/delhi-high-court-owns-up-to-plagiarism-charges-after-interns-gaffe/> accessed 22 December 2015; M Singh, 'After Intern Writes Judgment, Delhi HC Apologizes for 34-Paragraph Copy-paste Plagiarism', <http://www.legallyindia.com/bar-bench-litigation/afterintern-writes-judgment-delhi-hc-apologises-for-34-paragraph-copy-paste-plagiarism $>$ accessed 22 December 2015.

6. Novartis AG v Union of India (2013) 6 SCC 1.

7. F Hoffmann-La Roche v Cipla Ltd, revised judgment dated 8 December 2015 by the Delhi High Court (per Nandrajog and Gupta JJ) in RFA (OS) 92/2012 and 103/2012, at paragraphs 32 and $52<$ http://delhihighcourt.nic.in/dhcqrydisp_o.asp?pn=258821\&yr=2015> accessed 22 December 2015. All subsequent references to the appellate bench verdict are to this corrected version. 
In this case, the Court starts out attaching a straightforward meaning to the words of Section 3(d). ${ }^{8}$ However, this segues into an odd explanation of the Court's own understanding of some basic terms in chemistry - scientific terms given the legal treatment, if you will - in a manner that is simultaneously pedagogical and somewhat facile. $^{9}$

Next, the Court propounds a distinction under Indian law between mere 'substances' which are per se unpatentable by virtue of Section 3(d) and 'products' which are patentable under Section 48 (the rights conferring provision under Indian law) in the following words:

The use of the words 'product' and 'substance' in [the Indian Act] is therefore telling, in that the legislative intent appears clearly to demonstrate that all 'substances' may not qualify as 'products' under the Act, where the latter are only those substances that are patenteligible ...

... A new chemical entity that is structurally dissimilar but functionally similar to an existing chemical entity is thus merely a substance under Section 3(d). If the substance has an added layer of enhanced efficacy then it would be treated as a 'new product' and would be eligible for assessment ... to ascertain whether its formation involved an inventive step. If the new product involved one or more inventive steps, then it would qualify as a pharmaceutical substance. ${ }^{10}$

The overall impression is that, having worked its way to a sharp distinction it finds appealing, the Court is keen to shoehorn it into every available crevice in Section 3(d). There are two problems with this.

First, 'unpatentable substances' versus 'patentable products' simply is not the strict binary the Court insists it is. Section 3(d) itself recognizes as patentable new use(s) of a known substance where such a known substance is the subject of a process that involves one or more new reactants and meets the "significantly differing efficacy' standard. Such a 'substance' - an expression generic and broad enough in import to cover innumerable 'substances' - would be patentable. ${ }^{11}$

Second, the Court itself collapses this distinction when outlining what it considers a spectrum of patentability. It holds that any substance crossing the Section 3(d) efficacy threshold constitutes a 'new product' under Section 2(1)(j), even though this sub-section makes no mention of the expression 'new product'. ${ }^{12}$

8. Paragraphs $13-17$ and $28-29$.

9. 'Since we are dealing with inanimate objects', the Court says at paragraph 20, 'a product or a substance has to be a veritable being. Philosophically looked [sic], each inanimate object is, by virtue of its particularity and its limited and determinable form, different from and opposite to the genus - the particular contradicting the universal, so that the later does not fulfill itself in the former. When one talks of a substance being a veritable being, it would mean a real being, in the strict sense by which is meant the concrete individual thing. The individual thing is the subject or substance enduring throughout a movement in which it unifies and holds together the various states and phases of its existence'.

10. Paragraph 29.

11. Indeed, Section 3(d) is but one avenue that exposes the speciousness of this distinction the very next sub-clause in the Indian Act, Section 3(e), in effect, provides that a resultant substance that is not a mere admixture of reactants and displays properties that are more than the sum of its parts would be eligible for patentability.

12. Paragraph 29. 


\subsection{The 'double penalty'}

Further, any 'new product' that passes an inventive step, according to the Court, qualifies as a 'pharmaceutical substance' under Section 2(1)(ta). ${ }^{13}$ If this is true and 'pharmaceutical substance' is the top of the pyramid, why does Section 48, by the Court's own admission, extend rights only to 'products' and not 'pharmaceutical substances'? Further, why is 'substance' reductively defined as 'active ingredient' later ${ }^{14}$ in the judgment? The Court, disappointingly, answers neither question.

Even if this lack of clarity is regarded as purely academic, the Court goes further down this interpretive path, making practical conflict inevitable. It reasons:

What Section 3(d) certainly does NOT do, is doubly penalize the innovator, which appears to be the argument advanced by [Cipla] ... [T] aken to its logical conclusion, it would mean that a rejection of a polymorphic version of $[\mathrm{EH}] \ldots$ on the anvil of Section 3(d) would also result in effectively permitting all manufacturers of the said polymorph from being deemed noninfringers under Section $48 .{ }^{15}$

This begs the question of how the Court construes this to be a double penalty on the innovator. A double penalty would imply that a non-infringement finding on Polymorph B influences the infringement finding qua IN '774. This is not true. A 'double penalty' is a poor choice of terminology if what the Court intended to convey was that a rejection of Roche's patent for Polymorph B - at which point, by hypothesis, a Polymorph B formulation is fair game in the market - would have the consequence of, well, Polymorph B being fair game in the market. ${ }^{16}$

The Court goes on to say: 'The inherent assumption in [Section 3(d)] is that an infringement of the resultant product would therefore be an infringement of the original i.e. the known substance and by no stretch of imagination can Section 3(d) be interpreted as constituting a defence to infringement'. ${ }^{17}$

Leave aside the fact that Section 3(d) covers modifications to known substances in a manner that would very much constitute a defence to infringement. Further still, leave aside the impression that this reference to 'resultant product' seems to conflate 'product' and 'substance' in a manner that defeats the purpose of the several painstaking paragraphs devoted by the Court to this subject. The 'inherent assumption' the Court speaks of simply is not applicable here.

This is because Roche's own IN '507 application, filed after IN '774, was rejected by the Indian Patent Office, leaving no Section-48-protected 'resultant product' in the present case at all. Instead, this is a case where the 'resultant product' (if Polymorph B can be properly labelled as such) was read to be covered by 'the original substance' (EH, as disclosed in Claim 1 of IN '774) even without the original substance making any reference to - or, going by Cipla's best case, being created without the slightest hint of the existence of - the resultant product.

13. Paragraph 29.

14. Paragraph 31.

15. Paragraph 39.

16. Further, at paragraph 54, the Court says: 'Cipla's argument would shoot down the polymorph because of Section 3(d) and also attempts to shoot down the main compound, because of the polymorphs [sic] rejection. This cannot be done'. This is similarly confusing. If the polymorph and the main molecule are being tested on different metrics, then the outcome of which the Court appears to be apprehensive is merely that of separate rejections on independent thresholds. It is not immediately apparent why the Court thinks this 'cannot be done'.

17. Paragraph 40. 
Strangely, the Court appears to acknowledge this with its very next words:

While the suit patent covers [EH] (or polymorphs A+B of the same, if Cipla's [sic] contention were to be accepted), the rejection of the patent application for Polymorph B [IN '507] by the Indian Patent Office leads to a direct conclusion that there was a lack of sufficient matter to suggest that Polymorph B qualified as a 'new product' for consideration under Section 2(1)(j) for patentability and should therefore be regarded for all practical purposes as the old product itself i.e. Polymorphs $A+B .^{18}$

The emphasized portion is erroneous. If the IN ' 507 rejection is taken to mean that the new, resultant product is the old, patented product itself, as the Court suggests, why would Roche even consider re-patenting the exact same product? Why would it have done so under a fresh application, knowing that IN '774, at the time, still had over 14 years to run ${ }^{19}$ and would, except for a patent examination oversight of mindboggling rarity, be interpreted as inventive over IN ' 507 ?

Even over and above its failure to address this compelling absence of motivation, the initial reaction to the Court's findings on this issue is of confusion over whether the inquiry was correctly framed to begin with.

The issue here is not whether IN ' 774 can be read broadly enough to accommodate efficacious, subsequently discovered or commercialized polymorphs (something the Court rules decisively in favour of Roche on $)^{20}$ or even whether polymorphism in general and its hypothetical applicability to EH to yield potentially efficacious resultant products was in particular known prior to IN ' 774.

The question is simply whether, in the absence of any reference to polymorphs (which were not to be discovered for another three years), ${ }^{21}$ IN ' 774 could, with 2015 hindsight, be read to include a specific polymorph which Roche's own previous attempt at proprietorship failed to capture.

The Court's holding, in effect, means that the impossibility of creating Polymorph $\mathrm{B}$ without creating the patented $\mathrm{EH}$ molecule means that the reverse consequence necessarily follows, that is, every manufacturer of the EH molecule or the polymorph (or, indeed, any other polymorph, whether disclosed in the patent or not) will be an infringer. Surely, one feels, this outcome cannot be the import or legislative intent of Section 3(d).

\section{CONFUSION REIGNS}

\subsection{More uncredited passages}

Despite the Court having expunged parts of the original opinion which quoted unacknowledged portions from the 2013 article, several parts of the revised version issued on 8 December 2015 retain uncredited passages from the article. The overall effect, again, is of confusion and of difficulty in ascertaining how much of this is part of the Court's reasoning.

18. Paragraph 41 , emphasis added.

19. IN ' 507 was filed by Roche in February 2002.

20. Paragraphs $43-7$ and 49 .

21. Paragraph 48. 
The first significant passage of this nature ${ }^{22}$ is found in the Court's summary of proceedings before the Controller of Patents in relation to Roche's ultimately unsuccessful IN '507 application. Drawing verbatim from the 2013 article, ${ }^{23}$ the Court notes:

It is not in dispute that Roche's unsuccessful patent application in India [IN '507] was indeed for a 'Polymorph B' form of [EH], a claim which was rejected by the Controller of Patents in December 2008 with observations on ever greening, structural similarities between IN '774 and [IN '507] and a lack of conclusive comparative clinical data to prove efficacy. ${ }^{24}$

Worded as such, it reads like an endorsement of the Controller's rejection of IN '507. If so, it is unclear why the judgment later goes on to discuss with approval not just the IN '507 application in relation to its claimed 'superior' properties ${ }^{25}$ but also its US equivalent, in which Roche charts the synthesis of Polymorph B from EH. ${ }^{26}$

The second such instance appears in the Court's discussion of Cipla's defences to infringement. In capturing Cipla's arguments, the Court reproduces ${ }^{27}$ an uncredited paragraph from the 2013 article $^{28}$ that quotes the argument Cipla made before Justice Singh on the gap between Claim 1 of IN '774 and Tarceva (which was just Polymorph B).

Justice Singh, of course, held in part for both sides on this issue, and it remains unclear from this judgment whether, after Justice Singh's ambivalence towards this limb of their defence, Cipla did indeed adopt this same stance before this Court.

A third uncredited extract from the 2013 article $^{29}$ appears when dealing with Roche's rebuttal to this argument. ${ }^{30}$ Here, reference is made to a conclusion in the 2013 article - supported by Roche's disclosures in its US '221 patent (the American counterpart of IN '507 that proceeded to grant) - that the EH molecule was a necessary step in the synthesis of the Polymorph B version protected under US '221. It does not appear from the transcript recorded in the judgment that this stance was so canvassed by Roche, even though a general argument to this effect was evidently made. Therefore, once again, there is a damaging lack of clarity on whether this is a proper finding or merely an inactive observation.

\subsection{Product versus substance and $x$-ray diffraction}

The final and, by far, most significant uncredited reliance on the 2013 article is found in the observations I had made regarding the distinction between Tarceva and EH (as described in Claim 1 of IN '774) and Justice Singh's shifting use of the two in comparison with Erlocip as part of his infringement analysis. ${ }^{31}$ These observations have

22. Excluded for the present purpose is the last sentence of paragraph 1 of the Court's order, which reproduces part of paragraph 1 under the 'Background to the Roche/Cipla Dispute' subsection of the 2013 article. See note 2, at p. 168. However, this portion is merely descriptive of the efficacy of Roche's IN '774 patent and no legal conclusion turns on it.

23. See note 2, at paragraph 1 under 'The Section 3(d) Challenge' sub-section, at p. 171.

24. Paragraph 37.

25. Paragraphs $48-50$.

26. Paragraph 67.

27. Paragraph 64.

28. See note 2, at paragraph 2 under the 'The Infringement Question' sub-section, at p. 172.

29. See note 2, at paragraph 3 under the 'The Infringement Question' sub-section, at p. 172.

30. Paragraph 67.

31. See note 2 , at paragraphs $4-8$ under the 'The Infringement Question' sub-section, at pp. 172-3. 
been reproduced by the Court across five full paragraphs ${ }^{32}$ and identified by it as 'errors' ${ }^{33}$ in Justice Singh's reasoning.

While I stand by these observations, on which basis the Court says that Justice Singh was incorrect in using Tarceva and EH interchangeably, the Court's decision to use the observations to brush aside two related Cipla contentions is harder to defend. Cipla argued, first, that a patent needs to be over a commercial product ${ }^{34}$ and, second, that there is a discernible gap between Tarceva and the disclosures in IN ' $774 .{ }^{35}$ Both contentions are left unresolved.

Instead, the Court launches into its disapproval of Justice Singh's comments on x-ray diffraction (XRD) data, which were used to partly address the second of Cipla's contentions.

The Court concludes that XRD data is only ever relevant in a product patent case where the patent claim(s) and the Defendant's product are like substances. ${ }^{36}$ However, it simultaneously maintains that the door for XRD data would only be opened for a (patentee) product 'made on the basis of [the] patent claim' and that the patentee's actual product in the market is wholly irrelevant to such a comparison. ${ }^{37}$

This is unsettling, not least because it cuts off at a stroke all future reliance on XRD data except in the tiny fraction of cases where the product 'made on the basis of the patent claim' (an expression left unexplained) is presumably identical to the patentee's market product.

The stance is also odd for two further reasons. First, Justice Singh's reliance on XRD data was merely to establish whether Tarceva was exclusively Polymorph B. This much is clear not only from a reading of his opinion but is explicitly acknowledged by the Court earlier in this very judgment. ${ }^{38}$ (To be sure, this acknowledgement is part of the aforesaid uncredited five-paragraph passage from the 2013 article. Even so, its retention in the revised judgment can only be taken to represent the Court's endorsement.) It is evident, therefore, that XRD data was not used by Justice Singh as the sole piece of evidence on which to rest a test of infringement or to actually test infringement by checking if Tarceva and Erlocip were identical products. Yet, strangely, the Court repeatedly asserts that his reliance on XRD data was erroneous, ${ }^{39}$ contradicting its own previous acknowledgement of his reliance on the data for a more limited purpose.

Second, and more importantly though, even at the point where a product does manage to squeeze past these conditions, the Court's 'subtle distinction' 40 between the derived product and the market product is rendered ineffective by its very next ruling, which runs:

[T] he holder of a patent is, by no means, limited to only manufacture and sell only those products that are disclosed in the claims of the patent and hence a different polymorph manufactured by the patent holder which is not the subject of the registered patent cannot be

32. Paragraphs $68-72$.

33. Paragraphs 68 and 70.

34. Paragraph 56.

35. Paragraph 69.

36. Paragraphs $76-7$.

37. Paragraph 77.

38. Paragraph 69.

39. Paragraphs 74 and 78.

40. Paragraph 77. 
used for the purpose of comparison with the infringer product; the very product disclosed in the patent claims must be used. ${ }^{41}$

If one were to classify polymorph patents in a manner faithful to the instrumental justification implicit in the above passage, it would divide the field into two categories patents over molecules where polymorphism is undiscussed (such as IN '774) and patents over individual or multiple polymorphs of a molecule, whether or not the molecule itself remains unclaimed.

The Court's test is unhelpful in resolving tests for infringement by product comparison in both cases. The first category would, in the absence of an IN-'507-style improvement, cover all polymorphs, leaving Plaintiffs at liberty to pick their polymorph and thus bypass the derived product/market product distinction altogether.

The second category would merely narrow Plaintiffs' polymorph option(s) to those claimed, arguably with the overriding freedom to pick any polymorph that does not constitute a sole product claim in another granted patent (the expression 'which is not the subject of the registered patent' in the passage above strongly suggests this).

Further, in the latter scenario, Plaintiffs would inevitably retain the option to sue under the molecule patent, where one subsists, now entirely and decisively unfettered by the Court's decision to discard Justice Singh's view that IN '507 (or, more accurately, its patented American counterpart US '221) knifes IN '774. ${ }^{42}$

As such, the test seems to attach merely to outlier situations where Plaintiffs may use XRD or other product-specific data on specific polymorphs that are not the sole claims of polymorph patents in prior art to reel in infringing polymorphs to deceive judges. This is an unlikely scenario, and, at best, would aid judges seeking to weed out patent claims that are unworkable per se. This would be a desirable outcome but one which is not only almost certainly accidental but for which there exists adequate statutory protection in India. ${ }^{43}$

\subsection{Servier $v$ Apotex and conclusions on product infringement}

For confirmation of its view, the Court relies on a UK decision in Servier v Apotex. ${ }^{44}$ In Servier, a polymorph improvement patent filed around the time of the expiry of the Plaintiff's basic patent over a perindopril salt was dismissed by the UK Court of Appeals. However, this Court holds that the Court of Appeals' decision 'was not denying [the Plaintiff] the right to enforce the basic patent against a third party attempting to manufacture the [polymorph]', ${ }^{45}$ and that, similarly, Justice Singh ought to have construed Claim 1 of IN ' 774 to see if it encompassed Polymorph B.

This is puzzling. In Servier, the basic patent had already expired, so the question of interpreting and enforcing it to smother third party manufacture of polymorphs simply did not arise - Servier's action was for sustaining the polymorph patent alone and, in doing so, they were attempting to 'exploit the patent system as far as possible to protect that vast income stream (from the basic patent)' ${ }^{46}$

41. Paragraph 77, emphasis added.

42. See note 4 , at paragraphs 34 and 36 .

43. Section 146 of the Indian Patents Act, 1970, along with Rule 131 and Form 27 to the Indian Patents Rules, 2003.

44. [2008] EWHC Civ 445.

45. Paragraph 78.

46. See note 44 , at paragraph 4 . 
Further, using the Servier conclusion that the rejection of a polymorph patent for evergreening after the expiry of its basic patent to draw a parallel with the present case - where an active basic patent which pre-dates polymorphs was relied upon to cover a polymorph that was the subject of a later, rejected application - is extremely questionable. $^{47}$

To be sure, the Court notes that its decision to proceed with comparing Claim 1 of IN '774 with Erlocip on first principles was precipitated in no small part by the absence of any assistance from the parties' counsel on what the appropriate comparative should be - a caveat so important that it is stated twice in five paragraphs. ${ }^{48}$ Given that Claim 1 is agnostic to polymorphic content entirely, the ease with which the Court's final conclusion that Cipla's Polymorph B-based Tarceva infringes IN ' $774^{49}$ is arrived at is therefore a bit misleading.

The conclusion itself is a vexed one. On one hand, interpreting IN ' 774 to include all polymorphs despite no mention of polymorphs in the claims - as the Court has done reads the absence of an exclusion as a necessary inclusion. It does so with considerable hindsight, despite being prominently confronted with Roche's IN '507 rejection.

The conclusion also goes entirely against the grain of substantial interpretive work undertaken by the Court while discussing Section 3(d). In particular, the Court went on to say: '.. it cannot be presumed that once the patent/patent application for a new form of a known substance is rejected/abandoned then the said new form is covered under a prior patent relating to that substance' ${ }^{50}$ If no such presumption operates, it is hard to see where the reason(s) for applying it and thereby reading Polymorph B into IN '774 are to be found - they certainly have not been flagged as such, nor can they be read in by necessary implication. This is unfortunate because the factual standards for the applicability of such a presumption in Section 3(d) cases, if supplied, could potentially have been one of the biggest takeaways from the verdict.

The Court also reaches its conclusion without explaining whether and how polymorphs (and, in this case, Polymorph B in particular) are not mere 'new chemical entities' - structurally different but functionally similar iterations of known substances again, a category of substances that the Court emphatically denied patentability to under Section 3(d) earlier in this very judgment. ${ }^{51}$

On the other hand, it bears emphasizing that IN ' 774 was filed in March 1996, which is, literally and metaphorically, a lifetime by patent law standards. If the Court's interpretation sought to offer Roche a deserved largesse built on the back of a pioneering and remarkable discovery, then there is certainly merit in such a justification as well.

However, none of this is addressed by the Court itself. Indeed, it appears as if the Court's contribution to Indian law on this issue is more on what is not the appropriate

47. The general sense of confusion is heightened by the Court's initial observations on whether Claim 1 of IN ' 774 covers Polymorph B - the Court appears to answer the question in the affirmative ('it is therefore left to the Court to study the specification and claims of the suit patent and note that ... they would be infringed by any manufacture of Polymorph B by a third party') as well as the negative ('a conclusion that the IN ' 774 patent covers Polymorphs A+B itself is erroneous') in the space of the same paragraph. Paragraph 79.

48. Paragraphs 74 and 78 .

49. Paragraph 81.

50. Paragraph 18 . This is, to be sure, only half a presumption - the corollary to this arrives at paragraph 29 of the judgment, where the Court notes that built into Section 3(d) is the assumption that structurally similar derivatives of a known substance will also be functionally similar. 51. Paragraph 29. 
test for infringement rather than what is. As such, there does exist scope for the Court's position to be deviated from in the future.

\section{RULINGS ON NON-OBVIOUSNESS}

\subsection{Contentions and witness testimony}

The contentions canvassed by both parties on non-obviousness in this case distilled down to a single question - whether IN ' 774 was inventive over the closest prior art (Example 51 of EP '226), which also deployed quinazoline derivatives for their anti-cancer properties.

In sum, the parties agreed that the only difference between the two compounds was a methyl functional group at the 3-meta position in Example 51 of EP' 226 as against an ethynyl functional group at the same position in Claim 1 of IN ' 774.

Cipla claimed that prior art teaches a cyano substitution, ${ }^{52}$ which meant that a methyl-ethynyl substitution was well within the boundaries of obviousness, especially considering that methyl and ethynyl groups are widely known as bioisosteres and the roughly equivalent effectiveness landscape that the two compounds reside in. ${ }^{53}$

Roche's case, predictably, was a more defensive one, focusing on the non-obviousness and lack of scientific precedent for the 3-meta methyl-ethynyl switch, as well as attacks on the admissibility of Cipla's prior $\operatorname{art}^{54}$ and reliability of their scientific witness. ${ }^{55}$

In response, the Court quotes extensively from Indian and foreign precedent to feed a step-by-step legal process for testing obviousness that it proceeds not to apply. ${ }^{56}$ It ultimately rules that IN '774 was non-obvious.

Curiously, it does this solely by picking apart the witness's testimony based on his lack of personal knowledge of relevant prior art, ${ }^{57}$ an apparent hindsight bias in his reading of EP ' $226,{ }^{58}$ and the absence of testimony on bioisosterism, ${ }^{59}$ as well as because he 'looked at documents not available on the priority date being Google and Wikipedia' ${ }^{60}$ and his overall inability to meet the standards of the hypothetical skilled person (his own understanding was found to be inaccurate/incomplete). ${ }^{61}$

\subsection{Prima facie case for non-obviousness and In re Dillon}

Controversially, the Court rules that non-obviousness is a fluid burden across a trial, in that the Defendant is first required to set up a prima facie case of obviousness after which the burden shifts to the Plaintiff. ${ }^{62}$ In the circumstances, it holds that Cipla's

52. Paragraph 105.

53. Paragraph 105.

54. Paragraphs 105 and 109.

55. Paragraph 106.

56. Paragraph 118.

57. Paragraph 134(b), (c) and (k).

58. Paragraph 134(d), (g) and (h).

59. Paragraph 134(e).

60. Paragraph 134(f).

61. Paragraph 134(a), (i) and (j).

62. Paragraphs 125 and 135. 
failure to cross the prima facie threshold meant that Roche did not need to defend IN '774 on obviousness. ${ }^{63}$

This shifting burden is incorporated entirely from an American Federal Circuit minority ruling in In re Dillon. ${ }^{64}$ The majority view in Dillon holds that prior art need not echo the same suggestion, expectation or purpose as the claimed invention for it to be considered active in an obviousness inquiry. The minority view - which holds that such a similarity of purpose is necessary - reaches multiple findings that are incompatible with this Court's understanding of this dispute, which makes the reliance on it even more mystifying.

To wit, the Dillon minority states that the requirement of a prima facie case is to be used at the stage of patent examination (the present case is a post-trial appeal); that it is to be used to evaluate prior art that prompts a conclusion of unpatentability by the examiner (the present case uses it to reach a conclusion of patentability since the Defendant led unsatisfactory evidence); that the patentee can challenge such a finding with rebuttal evidence (the present case, having applied the standard in reverse, does not examine the patentee's evidence); and that the purpose of the prima facie standard is to better apportion burdens between the examiner and the patentee during patent prosecution (the present case uses it as an if-then standard, requiring the patentee to lead evidence only in select cases). ${ }^{65}$

In fact, even the portion quoted by the Court from the Dillon minority in support of the prima facie burden on the Defendant, ${ }^{66}$ apart from being incorrectly attributed to the case, ${ }^{67}$ also omits to mention 'in the words of Section $103^{\prime 68}-$ a reference to the expression 'the invention as a whole', which appears in 35 USC $\S 103$ and has no meaning under Indian law.

How, then, is Dillon an authority for this prima facie obviousness standard? Why was the minority relied on at all? What is the link between the similarity of purpose requirement advocated by the Dillon minority and the prima facie obviousness burden imposed on the Defendant? What is the value of the Dillon minority view given that it undercuts the Court's prima facie obviousness threshold? Even if legally sound, how is this obviousness burden to be discharged? The reliance on the Dillon minority poses these and a host of other questions that the Court, unhappily, does not engage with.

\section{OTHER FINDINGS}

\subsection{Non-disclosure of foreign prosecution history}

Cipla also claimed non-disclosure by Roche of the prosecution history of US '221/IN '507, which, it alleged, fell foul of Section 8 of the Indian Act, which requires the disclosure of all foreign prosecution history relating to the same or substantially the same

63. Paragraph 135.

64. 16 USPQ 2d 1897 (Fed Cir, 1990). Paragraph 121.

65. See note 64 , at paragraphs $173-5$.

66. '[T]he "idea" of new compounds is not separable from the properties that were sought by the inventor when making the compounds [and] structure and properties are essential components of the invention as a whole', says the Court at paragraph 124, citing from paragraph 165 of In Re Dillion.

67. The passage is originally from In re Cescon, 177 USPQ 264 and is merely cross-cited in Dillon.

68. See note 64, at paragraph 165 . 
invention. Roche's defence was that Cipla's pleadings disclosed no specific allegation to this effect and the bona fide belief that US '221 was not, for the purposes of Section 8, the same or a substantially similar invention qua IN '774.

In settling this issue, the Court relies on a recent Delhi decision which held that invalidation of the patent need not be the automatic outcome of an adverse Section 8 finding since Section 64(1)(m) of the Act allows for discretion in such cases. ${ }^{69}$ Accordingly, the Court holds that Roche's bona fides plus a functional disclosure in a 2007 opposition proceeding constituted 'substantial compliance'70 with Section 8. As such, the Court opts not to invalidate the patent, slotting it into a fast-expanding gap $^{71}$ between Section 8 and Section 64(1)(m).

\subsection{Claim construction}

One of the more promising contributions by this Court arrives when it caps a detailed summary of Indian and foreign precedent on the principles of claim construction with its own 16-point list. ${ }^{72}$ However, the list itself is more a description of what claims are rather than an aid to their construction. Then, despite promising to apply these principles to IN $774,{ }^{73}$ the Court never proceeds to do so.

Instead, while in the throes of an unconnected issue later in the judgment, the Court notes that 'the claim must be interpreted on its own language and, if it is clear, then resort cannot be had to subsequent statements or documents either to enlarge its scope or to narrow the same' ${ }^{74}$ As such, this is a far more useful principle than the 16 previously offered. However, it is totally against the run of context and does not set up a conclusion.

The closest the Court comes to reaching a finding in this area is when it interprets IN '774 to state that it protects 'a single molecular structure ... and therefore, irrespective of which polymorphic form it appears [in], it would have the same chemical structure as contained in Claim 1 of [IN '774]' ${ }^{75}$ Unfortunately, this is inconclusive in creating a legal basis to differentiate between molecule claims and polymorph claims and does not apply any principles of claim construction.

\subsection{Remedies}

With only a few months left until the expiry of IN '774, the Court, however, declines to injunct Cipla, despite finding in favour of Roche on all counts, explicitly informed by the fact that Cipla had been in the market ever since the institution of the original infringement proceedings in $2008 .^{76}$

Instead, it restores Roche's original infringement suit for the sole purpose of reviving Roche's plea for Cipla to reveal accounting data on its Erlocip sales and profits,

69. Sukesh Behl v Phillips Electronics 2015 (61) PTC 183 (Del).

70. Paragraphs 93 and 95.

71. Wockhardt Ltd v Novartis AG 2015 (62) PTC 589 (IPAB).

72. Paragraph 34.

73. Paragraph 35.

74. Paragraph 61.

75. Paragraph 44.

76. Paragraph 150. 
with directions to the subordinate judge to pass 'appropriate orders' ${ }^{77}$ presumably to estimate damages and costs, armed with Cipla's accounting disclosures.

The final line of the judgment imposes additional costs of INR 500000 $(\sim \mathrm{US} \$ 7500)^{78}$ - a nominal figure considering the scale of litigation but still a heavy award by the cripplingly antiquated standards of costs pay-outs in Indian intellectual property cases - but does not offer any reasoning whatsoever for the award.

\section{CONCLUSION}

The parting words of the 2013 article had emphasized how narrow the margin between victory and defeat had been for Roche and Cipla before Justice Singh. The appellate bench verdict is quite the opposite - definitive findings on advanced efficacy, product infringement, non-obviousness and foreign prosecution history disclosure, all of which add up to a resounding win for the rights-holder.

However, even leaving aside the publicity it has attracted on the plagiarism issue, the decision is hotly debatable on substance. The Court's findings on product versus substance, metrics of comparison in product infringement cases, tests for non-obviousness, $\mathrm{x}$-ray diffraction evidence, reliance on foreign precedent and a host of other substantive patent law issues range from the encouraging to the alarming.

It seems certain then, even at this early stage, that the 2015 Delhi High Court appellate bench judgment in the Roche/Cipla appeals will leave behind a legacy of controversy. 